\title{
Initial Cross-Over Test of A Positive Allosteric Modulator of Alpha-7 Nicotinic Receptors to Aid Cessation in Smokers With Or Without Schizophrenia
}

\author{
Kenneth A Perkins,', KN Roy Chengappa', Joshua L Karelitz', Margaret C Boldry', Valerie Michael', \\ Taylor Herb', Jessica Gannon', Jaspreet Brar', Lisa Ford ${ }^{2}$, Stefanie Rassnick ${ }^{2}$ and Darlene H Brunzell ${ }^{3}$ \\ 'Department of Psychiatry, WPIC, University of Pittsburgh School of Medicine, Pittsburgh PA, USA; ${ }^{2}$ Janssen Research and Development, Janssen \\ Pharmaceuticals, Titusville NJ, USA; ${ }^{3}$ Department of Pharmacology and Toxicology, Virginia Commonwealth University School of Medicine, \\ Richmond VA, USA
}

Preclinical research shows that compounds acting at $\alpha 7$ nicotinic receptors (nAChRs) can reduce nicotine self-administration, suggesting that a positive allosteric modulator (PAM) of $\alpha 7$ receptors, JNJ-39393406, may aid smoking cessation. Moreover, individuals with schizophrenia, who have very high rates of smoking, have reduced expression of $\alpha 7 \mathrm{nAChRs}$ and may particularly benefit from this compound. In two parallel studies using a within-subject cross-over design, 36 healthy smokers (Study I) and 62 smokers with schizophrenia (Study 2), both groups high in quit interest, attempted to initiate quitting temporarily during each of two 3-week phases. Treatments were the $\alpha 7$ nicotinic receptor PAM JNJ-39393406 (100 mg b.i.d.) or placebo (double-blind, counter-balanced). In each phase, all smoked ad lib with no drug on week I or during dose run-up on week 2, and then tried to quit every day during week 3 . Abstinence (confirmed by $\mathrm{CO}<5$ p.p.m.) and smoking reduction (CO <8), as well as cigarettes/day (in Study I), were assessed daily (MondayFriday) each quit week and compared between conditions. Secondary outcomes included abstinence symptoms (withdrawal and craving) and cognitive test responding ( $\mathrm{N}$-back; continuous performance task). In both studies, compared with placebo, active JNJ-39393406 did not increase the number of abstinent days nor reduce total smoking exposure. We also found no significant improvements in craving, withdrawal, or cognitive function. With this dose and study duration, our findings do not support further testing of this $\alpha 7$ nAChR PAM compound for possible efficacy in smoking cessation, in smokers with or without schizophrenia.

Neuropsychopharmacology (20I8) 43, I334-1342; doi: I 0.I038/npp.20 I7.292; published online 20 December 20I7

\section{INTRODUCTION}

Despite most smokers wanting to quit, the vast majority who try ultimately do not succeed, even with the best available therapeutics (Babb et al, 2017). Without more effective cessation medications, very low quit rates are likely to continue (eg, Hughes (2011)). Of dozens tested for potential efficacy in the past 30 years, only three first-line drugs have been approved by the FDA (nicotine replacement, bupropion, and varenicline), highlighting a need for more efficient screening of novel compounds that may warrant further development efforts (Lerman et al, 2007).

Acute intake of nicotine is critical for onset and maintenance of smoking (US Dept of Health and Human Services (USDHHS), 2010), and its actions at nicotinic acetylcholine receptors (nAChRs) in the brain are responsible for the reinforcing effects of cigarette smoking

*Correspondence: Dr KA Perkins, Department of Psychiatry, WPIC, University of Pittsburgh School of Medicine, 381I O'Hara Street, Pittsburgh, PA 15213, USA, Tel: + I 412246 5395, Fax: + I 412246 5390, E-mail: perkinska@upmc.edu

Received 28 August 2017; revised 20 October 2017; accepted 20 November 2017; accepted article preview online 29 November 2017
(DeNoble and Mele, 2006). Thus, in addition to the efficacious partial agonist varenicline (Mihalak et al, 2006), compounds acting at $\alpha 4$ and $\alpha 7 \mathrm{nAChRs}$ offer promise for aiding cessation. In particular, the orthosteric sites of nAChRs are the direct molecular targets of nicotine and the endogenous neurotransmitter $\mathrm{ACh}$, as nAChRs are cation channels that modulate neuron activity in brain areas that regulate mood, cognition, and reward (Brunzell, 2008). Preclinical studies show that activation of $\alpha 7 \mathrm{nAChRs}$ with a selective agonist significantly attenuates motivation to selfadminister nicotine (Brunzell and McIntosh, 2012), evidence supported by a study showing that galantamine, an $\alpha 7$ nAChR positive allosteric modulator (PAM), can also decrease nicotine intake in rats (Hopkins et al, 2012).

Consequently, selective stimulation of $\alpha 7 \mathrm{nAChRs}$ could prove effective for smoking cessation. The JNJ-39393406 compound, developed by Janssen Research and Development LLC, selectively potentiates nicotine and ACh activity at $\alpha 7$ nAChRs via binding to a separate, allosteric site and, therefore, is considered a PAM of $\alpha 7$ nAChRs. JNJ-39393406 PAM does not activate $\alpha 7$ nAChRs on its own but, in binding to an allosteric site (different from nicotine/ACh-binding site), enhances nicotine and ACh activity at $\alpha 7$ nAChRs (Winterer et al, 2013). So, 
JNJ-39393406 could decrease motivation to persist in smoking when trying to quit.

Moreover, preclinical findings may suggest possible efficacy of this compound for cessation in a specific and vulnerable subpopulation of highly dependent smokers, those with schizophrenia. Compared to the current $15 \%$ smoking prevalence in the general population, prevalence is nearly $70 \%$ in patients with schizophrenia, who tend to be very heavy smokers (De Leon and Diaz, 2005; Dickerson et al, 2013). Post mortem studies show that individuals with schizophrenia have reduced expression of $\alpha 7 \mathrm{nAChRs}$ (Freedman et al, 1995; Leonard et al, 2000; Mexal et al, 2010). Preclinical studies suggest JNJ-39393406 could aid cessation in smokers with schizophrenia by overcoming their likely deficit of $\alpha 7 \mathrm{nAChR}$ function (Adler et al, 1998). For these reasons, we hypothesized that JNJ-39393406-associated stimulation of $\alpha 7 \mathrm{nAChRs}$ would promote tobacco cessation, especially in smokers with schizophrenia.

In two parallel studies, we tested active JNJ-39393406 vs placebo for efficacy in cessation with separate samples of smokers already planning to quit soon: healthy smokers (Study 1) and smokers with schizophrenia (Study 2). To increase statistical power (Cohen, 1988), both studies used an efficient 'early Phase 2' cross-over procedure that we have validated for initial evaluation of a novel medication's potential efficacy for cessation (Perkins and Lerman, 2014). This procedure's specific objective is to quickly determine whether a novel medication does, or does not, show sufficient promise of efficacy to justify the substantial effort of a larger randomized Phase 2 clinical trial of that medication. The cross-over design enhances efficiency and statistical power because all participants receive both medication conditions, eliminating individual variability between conditions and allowing smaller sample sizes to test differences between conditions (Cleophas, 1993). Importantly, a key to the procedure's sensitivity and specificity is to conduct evaluations among smokers recruited for being high in quit interest (ie, already planning to permanently quit soon; Perkins, 2014).

In both studies, the primary outcome was number of days abstinent during each separate week-long 'practice' quit attempt under the two drug conditions manipulated in the cross-over design, active JNJ-39393406 vs placebo. Each drug condition was administered for 2 weeks following a baseline week, in counter-balanced order and double-blind. We also examined reductions in daily smoking exposure short of complete abstinence. In secondary outcomes to explore possible mechanisms of action, we assessed medication effects on abstinence-induced withdrawal and craving, and on cognitive function when abstinent.

\section{MATERIALS AND METHODS}

Nearly all procedures were common to both studies and so will be described once below. Those few procedures specific to one study or the other are noted as such.

\section{Recruitment}

As in sample sizes of comparisons for active drug $v s$ placebo in our prior studies using this procedure (Perkins and
Lerman, 2014), both studies aimed to recruit 60 smokers already intending to quit permanently in the next 2 months (ie, high in quit interest). Prospective participants in Study 1 were those from the Pittsburgh PA community responding to online or print ads, and in Study 2 were smokers with schizophrenia receiving outpatient treatment at the ambulatory clinics associated with Western Psychiatric Institute and Clinic (WPIC). All were recruited in November 2014 through March 2017, with follow-up ending May 2017. In both studies, after obtaining informed written consent, screening assessments included participants' smoking and health history, as well as their response to an open-ended question on when they hoped to make a permanent quit attempt (with study eligibility requiring next 2 months). Eligible subjects were required to be aged 18-65, smoke for $\geq 1$ year, and meet DSM-V criteria for nicotine dependence (American Psychiatric Association (APA), 2013), provide a mid-day screening $C O$ reading $\geq 10$ p.p.m. (SRNT Subcommittee on Biochemical Verification, 2002), and to not currently be taking cessation medication to help quit and no use of smokeless tobacco or electronic cigarettes in past month. (Other requirements specific to Study 2 are described below.) Screening also included assessment of alcohol use via the AUDIT (Saunders et al, 1993), as those with scores indicating dependence were excluded. Self-report of no more than 15 drinks per week and 3 drinks on any day in the past week was required.

Those not ineligible at screening received a physical exam by study physician, including EKG, bloodwork to check liver and kidney function (CBC, and so on), illicit drug screen (other than THC), urine pregnancy test (women), and interview to assess history of psychiatric disorders, suicidal ideation, current major health problems (eg, heart disease, diabetes) or contraindicated medications (eg, fentanyl, cyclosporine, pimozide, and quinidine). Smokers in Study 2 also had to have a total PANSS score of $\leq 70$ (Positive and Negative Syndrome Scale Score; Kay et al, 1987), which indicates severity of psychiatric symptoms. Those in Study 1 (only) were excluded if taking medications to treat serious psychological problems (eg, psychosis, anxiety disorders, and major depression). All confirmed as eligible were randomized to the two orders, either JNJ-39393406 ('JNJ') first or placebo first, with the other condition second in this crossover design.

Although Study 1 and Study 2 were each described as 'not a treatment study,' all prospective participants were told that one benefit included free open-label treatment with FDA-approved medication (bupropion in Study 1; their choice in Study 2) and brief counseling to make a permanent quit attempt after completing the study. No further participant payment would be provided, just assistance to quit smoking. This benefit was offered specifically to attract participation by smokers high in quit interest (Perkins and Lerman, 2014), as those not wanting to quit soon would be disinterested in such a study benefit lacking payment.

\section{Medication}

Active JNJ-39393406 (50 mg tablets), abbreviated here 'JNJ' and studied under IND \#122957, and matching placebo were supplied by Janssen Research and Development LLC 
(Titusville, NJ) and encapsulated by the WPIC Investigational Drug Service (IDS) research pharmacy. Study research staff and participants were blind to medication assignment by IDS (ie, double blind). To start the dose runup, participants took one capsule of JNJ-39393406 (50 mg), or identically appearing placebo, once on day 1 , incrementing by $50 \mathrm{mg}$ daily to reach $200 \mathrm{mg}$ by day 4 . The full dose involved two capsules, each twice per day (100 mg b.i.d. for JNJ), in the a.m. and evening, over the remaining 7 days of that medication condition, including the 5 -day practice quit period (Monday-Friday). One week of ad lib smoking followed the first quit attempt phase prior to the dose runup week with the other condition, to allow separate tests of each in aiding smoking abstinence. This active JNJ medication reaches peak blood levels after $3 \mathrm{~h}$, and the half-life is $\sim 6 \mathrm{~h}$ (Winterer et al, 2013), allowing for complete washout over the week, if administered as the first condition before starting the placebo condition. The dose of $200 \mathrm{mg}$ ( $100 \mathrm{mg}$ b.i.d.) was chosen because it was the largest dose previously tested in patients with schizophrenia, shows dose-dependent exposure in pharmacokinetic data and evidence of brain penetrance, and is welltolerated in patients also being treated with psychoactive medications (Winterer et al, 2013).

Compliance was $>97 \%$ for each medication condition in both studies, assessed by observation of a.m. dosing at each study visit (two visits in dose run-up week and five visits during the quit week), along with pill counts (Study 1) or blister packs (Study 2) at the end of each week. Across the total of 40 given per participant during each condition, means (SD) were just 1.2 (1.8) active JNJ and 0.9 (1.6) placebo missed for those in Study 1, and 0.6 (1.4) for active JNJ and 0.1 (1.1) for placebo missed among those in Study 2 .

\section{Measures}

Smoking outcomes. During the 'quit week' (week 3) of each condition, the primary outcome of 24-h abstinence was assessed daily on Monday-Friday by expired-air carbon monoxide $(\mathrm{CO})<5$ p.p.m., using a BreathCO CO monitor (Vitalograph; Lenexa KS). Depending on the type of CO monitor (Karelitz et al, 2017), this stringent biochemical criterion for validating cessation is more sensitive and specific than the traditional (higher) CO $<8$ cutoff (Perkins et al, 2013a). Yet, to gauge potential for smoking reduction short of complete abstinence, amount of daily smoking exposure was assessed in weeks 3 and 6 via CO $<8$ p.p.m., $\mathrm{CO}<10$ p.p.m. (Study 2 only), and cigarettes per day (Study 1 only) by a validated prospective selfmonitoring 'tally' form (Perkins et al, 2013).

Secondary outcomes. Also examined were abstinence symptoms of craving via Questionnaire of Smoking Urgesbrief (QSU) (Cox et al, 2001) and the Minnesota Nicotine Withdrawal Scale (MNWS) (Hughes et al, 1991), with each item scored on a 0-100 VAS. In Study 2 only, severity of psychiatric symptoms was also examined using the PANSS.

In addition, because the original purpose for developing this compound was to attenuate cognitive deficits in schizophrenia (Winterer et al, 2013), which can also occur upon smoking abstinence (Patterson et al, 2009, 2010), we assessed two measures of cognitive performance, the
Letter-N-back task of working memory (Ragland et al, 2002), and the Penn Continuous Performance Task (CPT) assessing sustained attention (Kurtz et al, 2001; Gur et al, 2010). Other details on assessing the tasks during smoking abstinence are presented elsewhere (Perkins et al, 2013b).

\section{Procedure}

In both studies, participation for each subject was 6 weeks after randomization, involving two 3 -week phases, one for each drug condition in this double-blind, cross-over procedure (see 3-week timeline in Supplementary Table S1). For each phase, visits occurred on Monday and on Thursday of the first 2 weeks and Monday-Friday of the third week. CO was assessed upon arrival to each session, along with QSU craving and MNWS withdrawal. Each phase began with a week of ad libitum smoking (baseline, week 1), with drug regimen started on Monday a.m. of week 2 while continuing to smoke (dose run-up). On week 3 , they were instructed to try to abstain as of Sunday a.m. through the mid-day Friday visit, with $\mathrm{CO}$ assessments of quit status on Monday-Friday of week 3. On Monday of week 3, all completed testing of cognitive function (N-back, CPT). Also, those in Study 1 reported number of cigarettes over the past $24 \mathrm{~h}$ on every day (Monday-Friday) of week 3, via the daily tallies. After Friday of week 3, all then ad lib smoked for at least a week to repeat this 3-week phase for the other condition: smoking without drug (ie, washout; week 4), next dose run-up (week 5), and trying to quit during MondayFriday (week 6).

Also assessed daily (Monday-Friday) of the two 'quit' weeks (weeks 3 and 6) were medication blinding and side effects. Effects were rated on a 0-3 scale (none, mild, moderate, severe) and included nausea, agitation, nervousness, constipation, dry mouth, fatigue, insomnia, headache, increased appetite, decreased appetite, and so on. When reported by participants, adverse events were also noted and addressed by study physician. EKG and bloodwork from the physical exam (above) were repeated at the end of weeks 2 and 5, and post study, to further evaluate safety. Finally, after study completion on Friday of week 6, all were offered the free regimen of medication and brief counseling (see the Recruitment section) for up to 8 weeks to help them make a permanent quit attempt. Both studies were approved by the University of Pittsburgh Institutional Review Board.

\section{Data Analysis}

Analyses were conducted using IBM SPSS 24.0. Preliminary analyses of variance (ANOVAs) examined effects of sex and of medication order between phases, finding no significant main or interaction effects. The primary outcome, number of days abstinent per assessment week (range of 0-5 days), was analyzed using paired $t$-tests (separately for $\mathrm{CO}<5$ and $\mathrm{CO}$ $<8$ p.p.m. criteria). Medication condition (active JNJ, placebo) was the within-subjects factor. Generalized estimating equations (GEEs) assessed differences between conditions for smoking reduction and for the secondary outcomes of craving and withdrawal, which were limited to only responses from days in which smoking abstinence was confirmed, separately by $\mathrm{CO}<5$ and then by $\mathrm{CO}<8$. In this way, recent exposure to nicotine via smoking would not 
confound symptom responses to medication condition. Results of cognitive testing were examined using paired $t$ tests for the CPT and RM ANOVA for the N-back. Medication condition was a within-subjects factor for both sets of analyses, with an additional within-subjects factor of memory load (0-, 1-, 2-, 3-back) for the N-back. Similar to analyses of craving and withdrawal, to detect potential efficacy of conditions on cognitive testing unconfounded by recent smoking, cognitive responses were analyzed only when $\mathrm{CO}<10$ on both the JNJ and placebo testing sessions, as in prior research (eg, Perkins et al, 2013b).

\section{RESULTS}

\section{STUDY 1-Healthy Smokers}

Participant characteristics. Due to greater than expected recruitment difficulty, only 36 healthy smokers (17 M, 19 F) were enrolled in Study 1. Mean (SD) characteristics were 37.6 (11.3) years of age, 16.2 (4.9) cigarettes per day, Fagerstrom test of nicotine dependence (FTND; Heatherton et al, 1991) score of 5.1 (1.6), and 2.1 (1.3) prior attempts to quit smoking. They mostly self-identified as Caucasian (72.2\%), with $19.4 \%$ as African-American, and $8.3 \%$ as more than one race. Five ( $3 \mathrm{M}, 2 \mathrm{~F})$ dropped out before finishing, two during week 1 (prior to any medication), two during week 2 (prior to the first quit period), and one during week 6, leaving 31 completing study participation. See Consort diagram for Study 1 in Figure 1.

Smoking outcomes. Mean (SE) abstinent days out of five (Monday-Friday) when attempting to quit on JNJ $v s$ placebo are shown in Figure 2, separately for the $\mathrm{CO}<5$ and $\mathrm{CO}<8$ cutoff criteria. In the primary analysis of paired $t$-tests in this within-subjects design, no significant effects on days abstinent were seen for medication condition, whether the criterion was $\mathrm{CO}<5, t(30)=1.06, p=0.30$, or $\mathrm{CO}<8$, $t(30)=0.00$, NS. In Study 1, GEE analysis showed that cigarettes per day for all participants was significantly more (although of modest absolute difference) during the quit attempt week for the JNJ vs placebo condition, with means (SEM) of 5.69 (0.76) vs 5.05 (0.61) per day, respectively, Wald $X^{2}(1)=4.64, p<0.05$. Thus, no efficacy was found for the JNJ drug $v s$ placebo in aiding smoking cessation or reduction.

Secondary outcomes. Craving and withdrawal. Selfreported craving and withdrawal were analyzed using GEE analyses. Compared to placebo, active JNJ actually increased QSU craving when CO $<5$, Wald $X^{2}$ ( 1 df)'s of 3.99, $p<0.05$, and when $\mathrm{CO}<8,10.35, p<0.005$, as also shown in Figure 2. For MNWS withdrawal, no significant differences were seen between placebo and active JNJ, when $\mathrm{CO}<5$, Wald $X^{2}(1 \mathrm{df})=0.50$, NS, although JNJ marginally increased withdrawal over placebo when $\mathrm{CO}<8$, Wald $X^{2}(1 \mathrm{df})$ of 3.11, $p=0.08$ (Figure 2).

Cognitive testing. As noted, analyses of cognitive results due to drug conditions during smoking deprivation was limited to the 12 subjects achieving $\mathrm{CO}<10$ on both the JNJ and placebo sessions. For the N-back (working memory), correct responses exceeded 75\%, demonstrating validity of comparing reaction time (RT) on correct responses by drug condition. Repeated measures ANOVA showed that median RT was significantly influenced by memory load

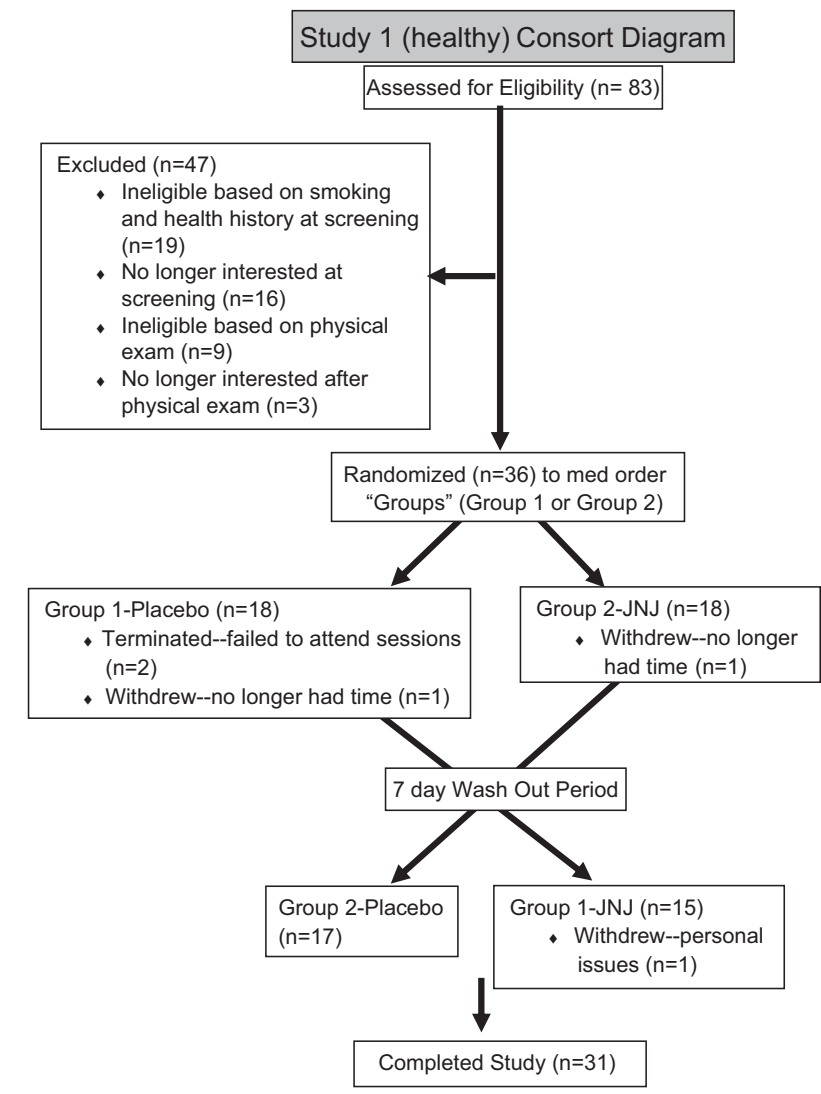

Figure I Consort diagram for Study I (with healthy smokers).

(0-, 1-, 2-, 3-back), $F(3,33)=4.65, p<0.01$, as expected, but only marginally by drug condition, $F(1,33)=3.23, p=0.10$, and not by the load $\times$ drug interaction, $F(3,33)<1$. As shown in Figure 3, median RT was non-significantly faster (better) for active JNJ vs placebo across memory loads. Correct responses on the CPT (sustained attention) was nearly $100 \%$. However, no significant effects of JNJ vs placebo were found on median RT (SE) in $\mathrm{ms}$ for responses to numbers using paired-samples $t$-tests, $429 \pm 15$ vs $418 \pm 8$, or letters, $460 \pm 16$ vs $458 \pm 12, t(11)$ 's of $1.30, p=0.22$, and of $0.12, p=0.91$, respectively.

Medication blinding, side effects, adverse events. During week 3 ('quit week') of each study phase, the percent of days that participants correctly identified the JNJ medication as 'active JNJ' was $14.2 \%$, compared to $9.7 \%$ as 'placebo (no medication)' and $75.5 \%$ as 'don't know.' For the placebo condition, very similarly, they correctly identified placebo on $11.6 \%$ of days, compared to $14.2 \%$ as 'active JNJ' and $74.2 \%$ as 'don't know.' None of these values differed by condition, indicating successful blinding. Side effects were mild, as most participants responded ' 0 ' (none) on the $0-3$ scale for each effect during both drug phases, and no effect mean was above 0.6 , with overall means (SD) of 0.20 (0.29) vs 0.23 $(0.27)$ for active JNJ $v s$ placebo, respectively, $t(30)=1.07$, $p=0.30$. Finally, few adverse events were reported, none serious or treatment-limiting. Most occurred with similar frequency during both drug conditions, although gastrointestinal discomfort (mostly nausea) appeared more likely for active JNJ vs placebo ( $n$ 's of 7 vs 2), while dermatological 
Study 1

(healthy smokers)

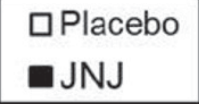

$\mathrm{CO}<5$

$\underline{\mathrm{CO}<8}$
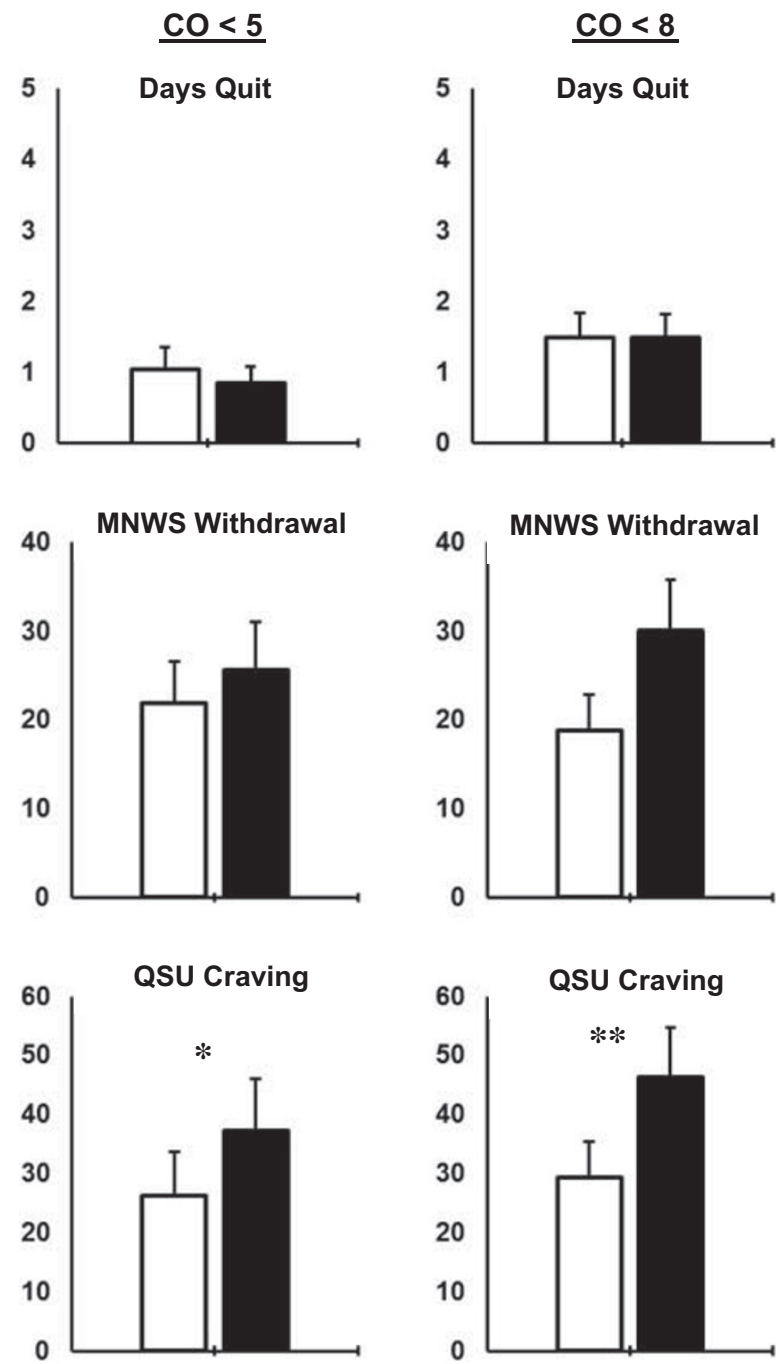

Figure 2 Study I means (SEM) for days quit (range 0-5), MNWS withdrawal, and QSU craving (both $0-100$ ), by JNJ vs placebo, when abstinence was biochemically verified by $\mathrm{CO}<5$ p.p.m., or $\mathrm{CO}<8$ p.p.m. * $p<0.05$, *** $p<0.005$ for differences between JNJ vs placebo.

(skin rash, and so on; 0 vs 3), body aches ( 1 vs 4), and psychological (sadness, and so on; 1 vs 5 ) events appeared less likely for active JNJ vs placebo.

\section{STUDY 2-Smokers with Schizophrenia}

Participant characteristics. For the 62 smokers with schizophrenia (37 M, 25 F; 30.6\% Caucasian, 69.4\% AfricanAmerican) randomized in Study 2, mean (SD) characteristics were 46.2 (11.1) years of age, 16.0 (7.1) cigarettes per day, FTND score of 6.0 (1.7), and 4.6 (13.8) prior attempts to quit smoking. Six (2 M, 4 F) dropped out (4) or were withdrawn (2) before finishing the study, leaving 56 completing study participation. See Consort diagram for Study 2 in Figure 4. All were being concurrently treated with antipsychotic medications $(80 \%$ on atypicals and $27 \%$ on typicals,

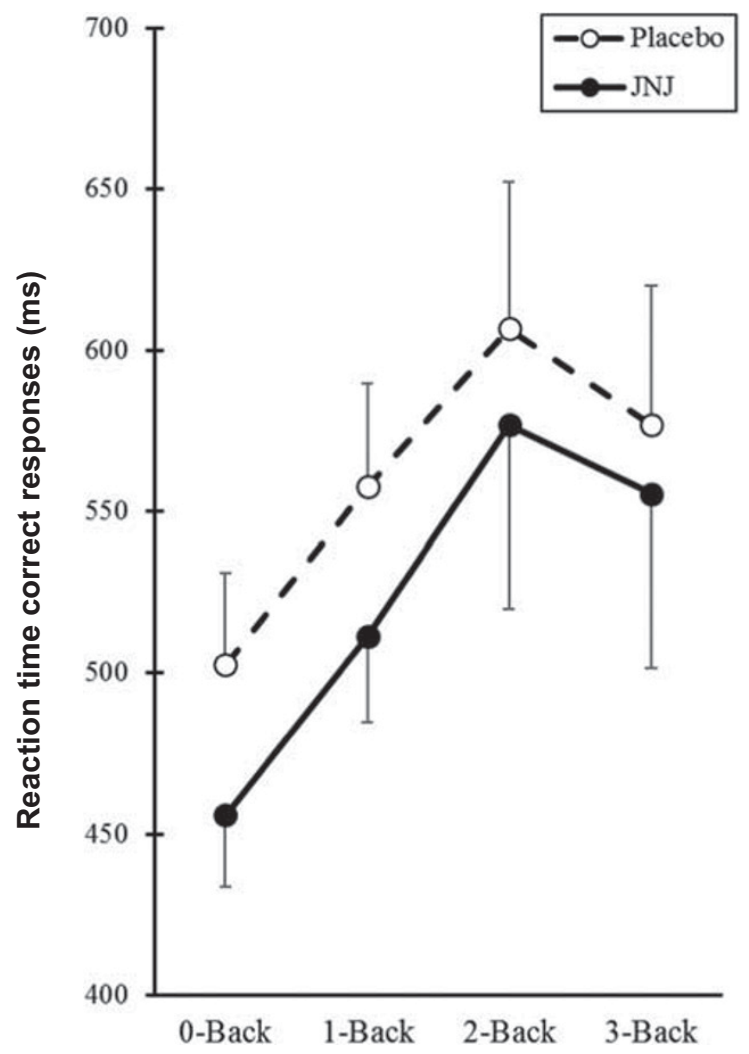

Figure 3 Study I means (SEM) for $\mathrm{N}$-back reaction time across memory loads (0-3), by JNJ vs placebo, when smoking reduction was biochemically verified by $\mathrm{CO}<10$ p.p.m.

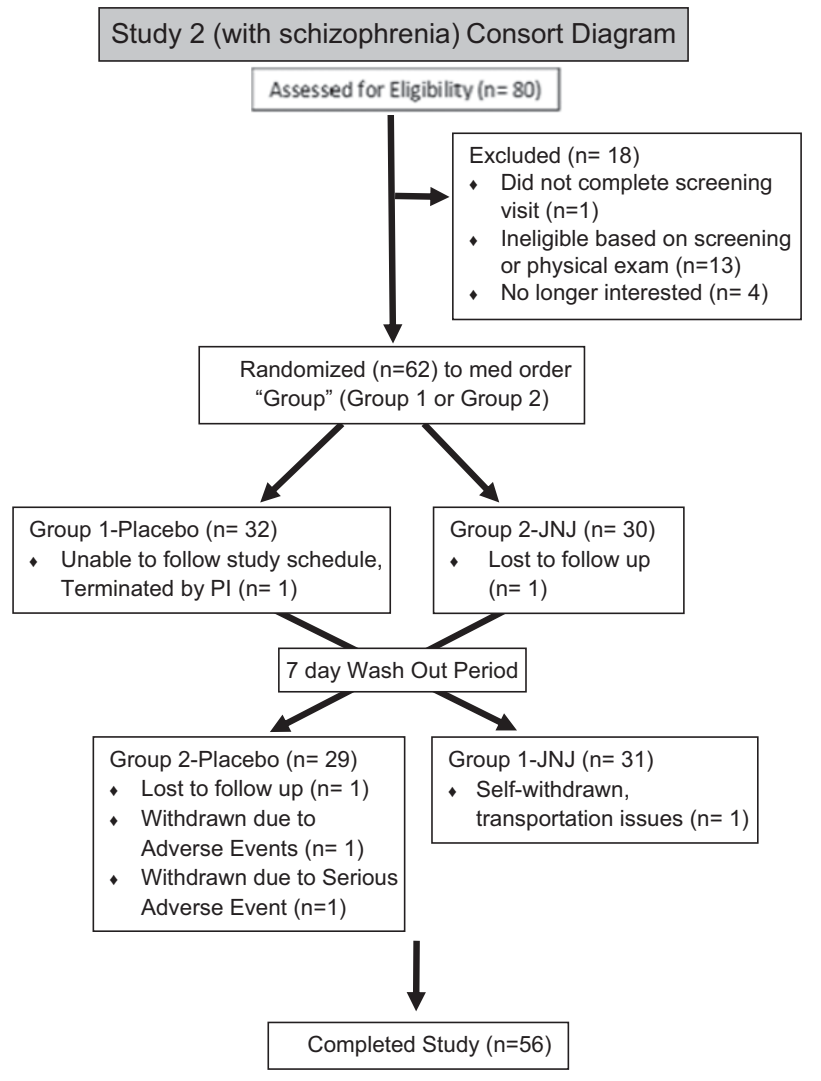

Figure 4 Consort diagram for Study 2 (smokers with schizophrenia). 
including those on more than one). Details include $39 \%$ on anti-depressants, $29 \%$ on mood stabilizers, $38 \%$ on anxiolytics/hypnotics, and $14 \%$ on anti-cholinergics.

Smoking outcomes. Mean (SE) abstinent days when attempting to quit on JNJ $v s$ placebo are shown in Figure 5 , by the $\mathrm{CO}<5$ and $\mathrm{CO}<8$ cutoff criteria, as in Study 1 . In paired $t$-tests, days abstinent did not differ by drug condition, whether $\mathrm{CO}<5, t(55)=0.78, p=0.44$, or $\mathrm{CO}<8, t(55)=0.85, p=0.40$. To more closely relate our results with many quit trials in psychiatric patients (eg, Chengappa et al, 2013; Tsoi et al, 2013), we also examined reduced smoking exposure using $\mathrm{CO}<10$ as a cutoff (SRNT Subcommittee on Biochemical Verification, 2002). Again, we found no differences due to drug condition, 0.93 (0.21) vs $1.00(0.23)$ days for JNJ $v s$ placebo, respectively, $t(55)=0.54$, $p=0.59$.

Secondary outcomes. Craving, withdrawal, and psychiatric symptom severity. As in Study 1, GEE analyses of craving and withdrawal were limited to days in which recent abstinence was confirmed by $\mathrm{CO}<5$ or $\mathrm{CO}<8$. No significant differences between active JNJ and placebo were found for QSU, MNWS, or in positive or negative psychiatric symptom severity, as well as total PANSS score (Figure 5).

Cognitive testing. In Study 2, comparisons between drug conditions on cognitive effects during smoking deprivation were limited to the seven subjects achieving $\mathrm{CO}<10$ on both sessions. However, compared to Study 1 (above), N-back correct responding out of 15 items per load was much lower, $<50 \%$ for loads above 0 -back, questioning the validity of comparing median RT for correct responding between conditions. Because of these low percentages of correct responses, we determined median $\mathrm{RT}$ for $\mathrm{N}$-back responding would not provide meaningful results, consistent with other studies of $\mathrm{N}$-back testing in patients with schizophrenia (Jansma et al, 2004; Frydecka et al, 2014). Yet, CPT correct responding was over $75 \%$ for both letters and numbers, indicating valid data, when one subject with 0 correct during placebo was excluded (ie, $n$ of 6 ). Using paired-samples $t$ tests, no significant differences were found during JNJ $v s$ placebo, respectively, on median (SEM) RT for numbers, $519 \pm 37$ vs $505 \pm 29$, or letters, $545 \pm 31$ vs $539 \pm 35, t(5)$ 's of $0.98, p=0.37$, and $0.44, p=0.68$.

Medication blinding, adverse events. During week 3 of each study phase, the percent of days that Study 2 participants correctly identified the JNJ medication as 'active JNJ' was $39.3 \%$, compared to $39.3 \%$ as 'placebo (no medication)' and $21.4 \%$ as 'don't know.' For the placebo condition, they correctly identified placebo on $37.5 \%$ of days, compared to $46.4 \%$ as 'active JNJ' and $16.1 \%$ as 'don't know.' These results by condition indicated successful blinding. Most subjects, $80.3 \%$, reported at least one adverse event, with some events appearing more common for active JNJ vs placebo, respectively (somnolence, $5 v s$, and fever, 4 vs 1), while others appeared less common for active JNJ $v s$ placebo (diarrhea, 4 vs 8; nausea, 4 vs 7; headache, 3 vs 5; muscle pain/soreness, 2 vs 5; and cold/nasal congestion, 2 vs 4). Cough was reported equally (3 vs 3 ). Three subjects experienced four total serious adverse events requiring hospitalization: pneumonia, acute diastolic congestive heart failure, persistent vomiting, and abdominal pain/vaginal

\section{Study 2 \\ (smokers with schizophrenia)}
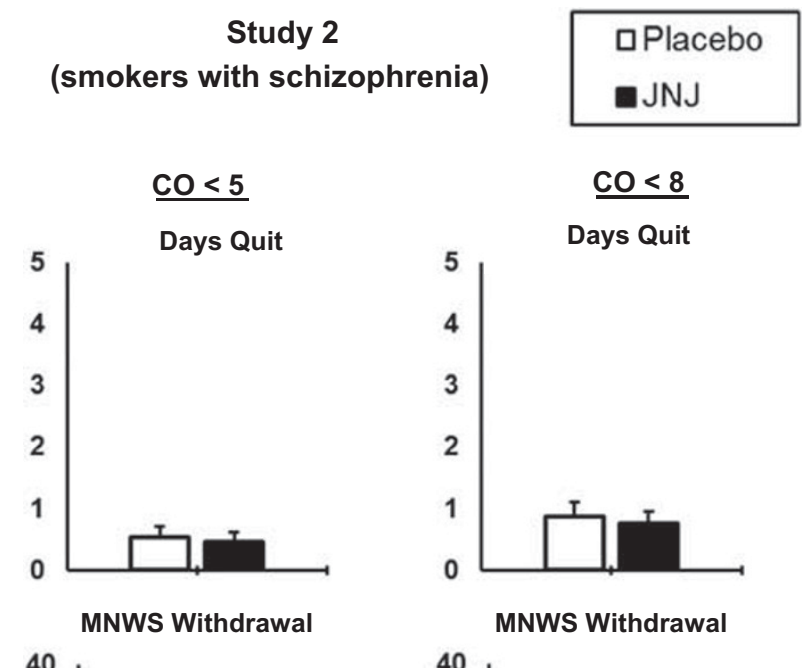

$\underline{\mathrm{CO}<8}$

Days Quit
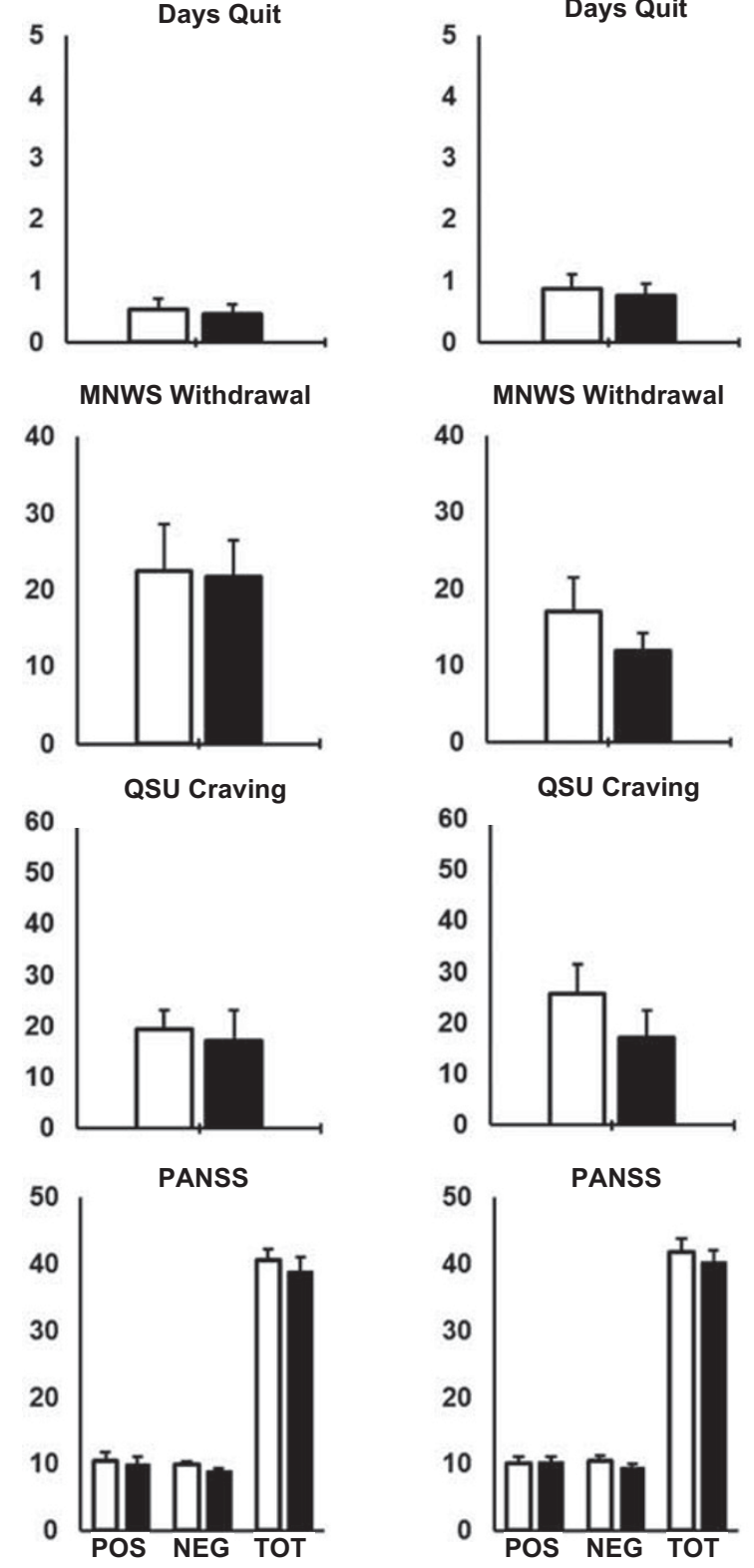

Figure 5 Study 2 means (SEM) for days quit (range 0-5), MNWS withdrawal, and QSU craving (both 0-100), and PANSS psychiatric symptom severity (pos and neg ranges are both 7-49; total score range is $30-210$ ), by JNJ vs placebo, when abstinence was biochemically verified by $\mathrm{CO}<5$ p.p.m., or $\mathrm{CO}<8$ p.p.m.

bleeding. All four serious adverse events were reported during the washout or placebo conditions.

\section{DISCUSSION}

Compared with placebo, the highly selective $\alpha 7 \mathrm{nAChR}$ PAM, JNJ-39393406, did not increase days quit during 
a brief practice quit period in dependent smokers high in current quit interest, whether otherwise healthy (Study 1) or with a diagnosis of schizophrenia (Study 2). In prior validity testing with healthy smokers, this cross-over procedure has demonstrated sensitivity in detecting clinical efficacy for each of the three first-line FDAapproved medications of nicotine patch, varenicline, and bupropion (Perkins and Lerman, 2014). It has also shown specificity in confirming lack of efficacy for modafinil (Perkins et al, 2013), a drug approved to help wakefulness but previously found ineffective for smoking cessation (Schnoll et al, 2008). Our procedure also recently found no evidence of efficacy for cessation with fenofibrate (Perkins et al, 2016), FDA-approved for lipid control and similar to fibrate drugs shown in preclinical research to reduce selfadministration of nicotine in rodent and primate models (Panlilio et al, 2012) and of alcohol in rodents (Haile and Kosten, 2017). Therefore, despite the potential promise of preclinical findings that suggest that stimulation of $\alpha 7$ nAChR reduces nicotine reinforcement and reward (Brunzell and McIntosh, 2012; Brunzell et al, 2014; Harenza et al, 2014), results of the current clinical studies indicate this Janssen $\alpha 7 \mathrm{nAChR}$ PAM, at the dose and duration tested, lacks clinical efficacy in aiding ability of dependent smokers to quit smoking. Yet, even with this validated cross-over design, the optimum dosing and treatment regimen for detecting efficacy may prove challenging with novel compounds.

Although Study 1 tested just 31 healthy smokers completing both phases, Study 2 in 56 smokers with schizophrenia found virtually identical lack of efficacy for cessation (stringently verified by $\mathrm{CO}<5$ ) in this JNJ drug vs placebo, demonstrating replication of the Study 1 findings. That $N$ of 56 is comparable or larger than our prior studies demonstrating sensitivity of this cross-over procedure (Perkins and Lerman, 2014). Both current studies also found no evidence of better outcomes with JNJ vs placebo on the other smoking behavior measures (cigarettes per day in Study $1, \mathrm{CO}<8$ in both studies, and so on), or on secondary measures of craving or withdrawal during abstinence, consistent with lack of cessation efficacy for this $\alpha 7 \mathrm{nAChR}$ PAM. Surprisingly, the dose of JNJ compound used in these studies led to increased craving compared to placebo in Study 1 participants able to reduce smoking as measured by $\mathrm{CO}<5$ and $\mathrm{CO}<8$ p.p.m. (Figure 2). However, our findings could be specific to the brief duration, procedures used, and single dose tested. Longer duration and a broader dose range of this or perhaps other $\alpha 7 \mathrm{nAChR}$ PAMs may show efficacy for smoking cessation (eg, Marcus et al, 2016; Gee et al, 2017).

We also found no evidence of the JNJ drug's efficacy in improving responding on cognitive tests of working memory and sustained attention during smoking reduction (CO $<10$ ). This null finding should be tempered by the small samples of smokers able to meet the $\mathrm{CO}<10$ criterion, as well as the inability of the smokers with schizophrenia in Study 2 to respond correctly on the N-back task. Yet, finding no beneficial effects of the JNJ compound on cognitive performance may be similar to a recent study showing no effects of JNJ-39393406 on reversing deficits in event-related potential (ERP) P50 sensory gating via EEG in non-abstinent male smokers with schizophrenia (Winterer et al, 2013). On the other hand, Study 2 constitutes the first use in smokers with serious mental illness of our early Phase 2 cross-over procedure to evaluate cessation efficacy in novel compounds vs placebo, showing some feasibility despite the difficulty achieving abstinence here with either drug condition. Finally, this JNJ compound was safe and well-tolerated in both studies, and it may be worth noting that psychiatric symptoms of smokers with schizophrenia in Study 2 were not worsened by either condition, including in those able to abstain from smoking during the brief practice quit periods.

To conclude, results of the current studies do not provide support for proceeding with this $\alpha 7 \mathrm{nAChR}$ PAM, at the dose and duration tested, to a larger clinical trial randomizing treatment-seeking smokers, with or without schizophrenia, to permanently quit smoking.

\section{FUNDING AND DISCLOSURE}

This research was supported by NIH Grant UH3 TR000958 from NCATS (Brunzell, Perkins). The sponsor of the study had no role in study design, data collection, data analysis, data interpretation, or writing of the report. Janssen Research and Development LLC (JRD) supplied the active JNJ-39393406 compound and matching placebo, and JRD had input into the planning, execution, and reporting of this research. Drs KAP and KNRC had full access to all the data and take full responsibility for the integrity of the data and accuracy of the data analysis. The authors declare no conflict of interest.

\section{ACKNOWLEDGMENTS}

We thank Jeffrey Nye MD and Carla Canuso MD (at JRD) for assistance in study planning, as well as Joseph Carley, MD, Drew Calhoun, MD, Patricia Schlicht, RN, Courtney Abegunde, MA, Kelley Wood, BS, and Joan Spinogatti, AS at the University of Pittsburgh for their excellent assistance throughout all phases of conducting this research.

\section{REFERENCES}

Adler LE, Olincy A, Waldo M, Harris JG, Griffith J, Stevens K et al (1998). Schizophrenia, sensory gating, and nicotinic receptors. Schizophr Bull 24: 189-202.

American Psychiatric Association (APA) (2013). Diagnostic and Statistical Manual-V. American Psychiatric Association: Washington DC, USA.

Babb S, Malarcher A, Schauer G, Asman K, Jamal A (2017). Quitting smoking among adults-United States, 2000-2015. MMWR Morb Mortal Wkly Rep 65: 1457-1464.

Brunzell DH (2008). Neurochemistry of nicotine dependenceIn: Karch SBed Neurochemistry of Abused Drugs. CRC Press, Taylor and Francis: Boca Raton, FL, USA. pp 23-33.

Brunzell DH, McIntosh JM (2012). Alpha7 nicotinic acetylcholine receptors modulate motivation to self-administer nicotine: implications for smoking and schizophrenia. Neuropsychopharmacol 37: 1134-1143.

Brunzell DH, McIntosh JM, Papke RL (2014). Diverse strategies targeting $\alpha 7$ homomeric and $\alpha 6 \beta 2^{*}$ heteromeric nicotinic acetylcholine receptors for smoking cessation. Ann NY Acad Sci 1327: 27-45. 
Chengappa KNR, Perkins KA, Brar JS, Schlicht PJ, Turkin SR, Hetrick ML et al (2013). Varenicline for smoking cessation in bipolar disorder: a randomized, double-blind, placebocontrolled study. J Clin Psychiatry 75: 765-772.

Cleophas TJM (1993). Cross-over studies: a modified analysis with more power. Clin Pharmacol Ther 53: 515-520.

Cohen J (1988). Statistical Power Analysis For The Social Sciences, 2nd edn. Lawrence Erlbaum Associates: Hillsdale, NJ, USA.

Cox LS, Tiffany ST, Christen AG. (2001). Evaluation of the brief questionnaire of smoking urges (QSU-brief) in laboratory and clinical settings. Nicotine Tob Res 3: 7-16.

De Leon J, Diaz FJ (2005). A meta-analysis of worldwide studies demonstrates an association between schizophrenia and tobacco smoking behaviors. Schizophr Res 76: 135-157.

DeNoble VJ, Mele PC (2006). Intravenous nicotine selfadministration in rats: effects of mecamylamine, hexamethonium and naloxone. Psychopharmacology 184: 266-272.

Dickerson F, Stallings CR, Origoni AE, Vaughan C, Khushalani S, Schroeder J et al (2013). Cigarette smoking among persons with schizophrenia or bipolar disorder in routine clinical settings, 1999-2011. Psychiatr Serv 64: 44-50.

Freedman R, Hall M, Adler LE, Leonard S (1995). Evidence in postmortem brain tissue for decreased numbers of hippocampal nicotinic receptors in schizophrenia. Biol Psychiatry 38: 22-33.

Frydecka D, Eissa AM, Hewedi DH, Ali M, Drapala J, Misiak B et al (2014). Impairments of working memory in schizophrenia and bipolar disorder: the effect of history of psychotic symptoms and different aspects of cognitive task demands. Front Behav Neurosci 8: 416 .

Gee KW, Olincy A, Kammer R, Johnson L, Hogenkamp D, Harris J et al (2017). First in human trial of a type I positive allosteric modulator of alpha 7-nicotinic acetylcholine receptors: pharmacokinetics, safety, and evidence for neurocognitive effect of AVL-3288. J Psychopharmacology 31: 434-441.

Gur RC, Richard J, Hughett P, Calkins ME, Macy L, Bilker WB et al (2010). A cognitive neuroscience-based computerized battery for efficient measurement of individual differences: standardization and initial construct validation. J Neurosci Methods 187: 254-262.

Haile CN, Kosten TA. (2017). The peroxisome proliferatoractivated receptor alpha agonist fenofibrate attenuates alcohol self-administration in rats. Neuropharmacol 116: 364-370.

Harenza JL, Muldoon PP, De Biasi M, Damaj MI, Miles MF (2014). Genetic variation within the Chrna7 gene modulates nicotine reward-like phenotypes in mice. Genes Brain Behav 13: 213-225.

Heatherton TF, Kozlowski LT, Frecker RC, Fagerstrom K-O. (1991). The Fagerstrom test for nicotine dependence: a revision of the Fagerstrom tolerance questionnaire. $\mathrm{Br} J$ Addict 86: 1119-1127.

Hopkins TJ, Rupprecht LE, Hayes MR, Blendy JA, Schmidt HD (2012). Galantamine, an acetylcholinesterase inhibitor and positive allosteric modulator of nicotinic acetylcholine receptors, attenuates nicotine taking and seeking in rats. Neuropsychopharmacol 37: 2310-2321.

Hughes JR (2011). The hardening hypothesis: is the ability to quit decreasing due to increasing nicotine dependence? A review and commentary. Drug Alcohol Depend 117: 111-117.

Hughes JR, Gust SW, Skoog K, Keenan RM, Fenwick JW. (1991). Symptoms of tobacco withdrawal. Arch Gen Psychiatr 48: 52-59.

Jansma JM, Ramsey NF, van der Wee NJA, Kahn RS. (2004). Working memory capacity in schizophrenia: a parametric fMRI study. Schizophr Res 68: 159-171.

Karelitz JL, Michael VC, Perkins KA (2017). Analysis of agreement between expired-air carbon monoxide monitors. J Smok Cessat 12: 105-112.
Kay SR, Fiszbein A, Opler LA (1987). The positive and negative syndrome scale (PANSS) for schizophrenia. Schizophr Bull 13: 261-276.

Kurtz MM, Ragland JD, Bilker W, Gur RC, Gur RE (2001). Comparison of the continuous performance test with and without working memory demands in healthy controls and patients with schizophrenia. Schizophr Res 48: 307-316.

Leonard S, Breese C, Adams C, Benhammou K, Gault J, Stevens K et al (2000). Smoking and schizophrenia: abnormal nicotinic receptor expression. Eur J Pharmacol 393: 237-242.

Lerman C, LeSage MG, Perkins KA, O'Malley SS, Siegel SJ, Benowitz NL et al (2007). Translational research in medication development for nicotine dependence. Nat Rev Drug Dev 6: 746-762.

Marcus MM, Bjorkholm C, Malmerfelt A, Moller A, Pahlsson N, Konradsson-Geuken A et al (2016). Alpha7 nicotinic acetylcholine receptor agonists and PAMs as adjunctive treatment in schizophrenia. An experimental study. Eur Neuropsychopharmacol 26: 1401-1411.

Mexal S, Berger R, Logel J, Ross RG, Freedman R, Leonard S (2010). Differential regulation of alpha7 nicotinic receptor gene (CHRNA7) expression in schizophrenic smokers. J Mol Neurosci 40: 185-195.

Mihalak KB, Carroll FI, Luetje CW. (2006). Varenicline is a partial agonist at alpha4beta 2 and a full agonist at alpha 7 neuronal nicotinic receptors. Mol Pharmacol 70: 801-805.

Panlilio LV, Justinova Z, Mascia P, Pistis M, Luchicchi A, Lecca S et al (2012). Novel use of a lipid-lowering fibrate medication to prevent nicotine reward and relapse: preclinical findings. Neuropsychopharmacol 37: 1838-1847.

Patterson F, Jepson C, Loughead J, Perkins K, Strasser AA, Siegel S et al (2010). Working memory deficits predict short-term smoking resumption following brief abstinence. Drug Alcohol Depend 106: 61-64.

Patterson F, Jepson C, Strasser AA, Loughead J, Perkins KA, Gur RC et al (2009). Varenicline improves mood and cognition during smoking abstinence. Biol Psychiatry 65: 144-149.

Perkins KA. (2014). Improving efficiency of initial tests for efficacy in smoking cessation drug discovery. Exp Opin Drug Discov 9: 1259-1264.

Perkins KA, Jao NC, Karelitz JL (2013). Consistency of daily cigarette smoking amount in dependent adults. Psychol Addict Behav 27: 723-729.

Perkins KA, Karelitz JL, Jao NC (2013a). Optimal carbon monoxide criteria to confirm 24-hr smoking abstinence. Nicotine Tob Res 15: 578-582.

Perkins KA, Karelitz JL, Jao NC, Gur RC, Lerman C (2013b). Effects of bupropion on cognitive performance during initial abstinence. Drug Alcohol Depend 133: 283-286.

Perkins KA, Karelitz JL, Michael VC, Fromuth M, Konklin CA, Chengappa KNR, Hope C, Lerman C (2016). Initial evaluation of fenofibrate for efficacy in aiding smoking abstinence. Nicotine Tob Res 18: 74-78.

Perkins KA, Lerman C (2014). An efficient early Phase 2 procedure to screen medications for efficacy in smoking cessation. Psychopharmacology 231: 1-11.

Perkins KA, Lerman C, Karelitz JL, Jao NC, Chengappa KNR, Sparks GM (2013). Sensitivity and specificity of a procedure for early human screening of novel smoking cessation medications. Addiction 108: 1962-1968.

Ragland JD, Turetsky BI, Gur RC, Gunning-Dixon F, Turner T, Schroeder L et al (2002). Working memory for complex figures: an fMRI comparison of letter and fractal n-back tasks. Neuropsychol 16: 370-379.

Saunders JB, Aasland OG, Babor TF, de la Fuent JR, Grant M. (1993). Development of the Alcohol Use Disorders Identification Test (AUDIT): WHO collaborative project on early detection of persons with harmful alcohol consumption-II. Addiction 88: 791-804. 
Schnoll RA, Wileyto EP, Pinto A, Leone F, Gariti P, Siegel S et al (2008). A placebo-controlled trial of modafinil for nicotine dependence. Drug Alcohol Depend 98: 86-93.

SRNT Subcommittee on Biochemical Verification (2002). Biochemical verification of tobacco use and cessation. Nicotine Tob Res 4: 149-159.

Tsoi DT, Porwal M, Webster AC. (2013). Interventions for smoking cessation and reduction in individuals with schizophrenia. Cochrane Database Syst Rev 2: CD007253.
US Dept of Health and Human Services (USDHHS) (2010). How Tobacco Smoke Causes Disease: The Biological and Behavioral Basis for Smoking-Attributable Disease. (A Report of the Surgeon General.). USDHHS: Atlanta, GA, USA.

Winterer G, Gallinat J, Brinkmeyer J, Musso F, Kornhuber J, Thuerauf $\mathrm{N}$ et al (2013). Allosteric alpha-7 nicotinic receptor modulation and P50 sensory gating in schizophrenia: a proof-ofmechanism study. Neuropharmacol 64: 197-204.

Supplementary Information accompanies the paper on the Neuropsychopharmacology website (http://www.nature.com/npp) 